\title{
Implications of Parents' Socio-Economic Status in the Choice of English Language Learning Strategies among Nigeria's Secondary School Students
}

\author{
Mallam Adamu Babikkoi ${ }^{1,2}$ \& Noor Zainab binti Abdul Razak ${ }^{1}$ \\ ${ }^{1}$ Universiti Teknologi Malaysia, Malaysia \\ ${ }^{2}$ Federal College of Education, Yola, Nigeria \\ Correspondence: Mallam Adamu Babikkoi, Universiti Teknologi Malaysia, Malaysia. E-mail: \\ abalbashar5@yahoo.com
}

Received: March 31, 2014 Accepted: June 30, 2014 Online Published: July 15, 2014

doi:10.5539/elt.v7n8p139 URL: http://dx.doi.org/10.5539/elt.v7n8p139

\begin{abstract}
Studies have indicated that, less affluent families are less likely to have the financial and or time availability to provide their children with academic support compared to affluent families.This study investigated the relationship between Language Learning Strategies used by secondary school students in Nigeria and their Parents Socio-economic Status. The data for this research was provided by 559 respondents who study English as a second language and belonging to three varied socio-economic affiliations. A modified Oxford Study Inventory of Language Learning (SILL) questionnaire was used as the measurement instrument. Analysis of the data was done using SPSS version 16.0. This was done to assess the strategies employed and to understand their mean frequencies. A one-way ANOVA was conducted to determine the relationship between language learning strategy choice and socio-economic status of student's parents. The study found that, respondents highly used Language Learning Strategy (LLS) while learning English and within closely related frequency level. The study found significant relationship between socio-economic statuses of parents of the learner in the choice of Cognitive, Metacognitive, Social, situational and religious Strategies and no significance in the learner choice of Memory and compensation strategies to learn English. Conclusively, the findings of the study has pedagogical implications for English Language teachers and curriculum designers that could assist in understanding the English language learning patterns of secondary school students in Nigeria.
\end{abstract}

Keywords: language learning strategies, secondary school students, second language, foreign language, English learning, Nigeria

\section{Introduction}

The field of Second Language Acquisition (SLA) focuses on the identification and pattern of learning strategies employed by ESL learners and the correlation of those strategies with other variables such as gender, proficiency level, age, belief, motivation, classroom situation, and examinations, etc. Learning strategies as conscious ideas and actions that ESL learners employ to be able to achieve a learning goal is of interest to many in the field of social and cognitive psychology, linguistics and language pedagogy (El-Dibb, 2004). Learning strategies exposes the learner's metacognition as regard to their own thinking and learning approaches, a great knowledge of exactly what a task entails, and the opportunity to use the strategies that best meet both task demands as well as their own learning talents.

Studies involving language learners often reveal that the most successful learners employ learning strategies that are quite suitable not only to the task, but also to the learning material, self-objectives, needs, motivation and stage of learning (Mohammed, 2000; Oxford, 2003). This is an indication that, effective ESL/EFL learners succeed through employing appropriate learning strategies, whereas the ineffective learners seldom employ appropriate learning strategies. It is quite evident that the choice of learning strategy is a child of many factors. Oxford (2003) further maintains that, learning strategies are employed differently and has the potentials of influencing the individual learner's proficiency, confidence and lower anxiety. Therefore, investigating the learners' strategy use in the context of their varying characteristics such as socio-economic status of their parent and what effect such a variable can exert in influencing the choice of language learning strategies is no doubt 
vital because it significantly contributes to learners' meta-cognition and improvement strategies as it affects English language pedagogy. The learning pattern of English language in Nigeria's secondary schools does not encourage self learning as such (Oluwole, 2008; Adeyemi, 2011). The relationship between Eglish language proficiency and academic performance help the learner to understand all subecjt. Any stattegies that will enhance learning is worth researching on (Adeyemi, 2007).

English is central to the Nigeria's system largely because it is the official language of administration, teaching and learning and the language of science and technology. In Nigeria English language is widely accepted and used such that it is seen as assuming a status even above the indigenous ancestral languages (Osbon, 2007; Abimbola, 2010). English language is the medium of instruction in almost all subjects in the school system; as such competence in English language is seen as a sure gateway to understanding other school subjects. According to Ezergu (2010), in Nigeria every school going child is a potential English Language learner, from nursery through to the University level. In addition, as Munkaila and Haruna (2001) rightly put, the ability to competently communicate in the language of the colonial master is appreciated so much as it carries with it some privileges, power and prestige.

According to Jaiyeoba and Atanda (2011), poor English proficiency is a leading factor for poor academic achievement at all levels. In this regard Oyetade (1990) maintains that there has to be a change in the English learning attitude among Nigerian students because attitude to language underpins planning strategies and therefore plays a crucial role in serving as a determiner of competence. The dwindling performance of Nigerian secondary school students in Senior Secondary School Examination (SSCE) have been a matter of concern to educationists, parents and policy-makers (Oluwoye, 2008; Adeyemi, 2012; Matthew, 2013) since 2005. Some studies traced the problem to the students' poor English proficiency. English language in Nigerian context is essential in determining the general performance of students because almost all school subjects are taught using English language as the medium of instruction. Studies have revealed that, employing appropriate learning strategies influence positively the learning of ESL (Oxford, 1990; Oxford et al., 2004).

This paper assesses the language learning strategies (LLS) used by secondary school students in Nigeria to learn English. In addition, it examines the relationship between the socio-economic status of parents of the learners and their LLS choice. Suggestions are made for future research focused on the relationship between learning strategies and other variables such as religion, school mode and school location.

\subsection{Current Issues in English Language Learning in Nigeria}

In an education system which adopts English language as the sole language of instruction, the excellent mastery of the language of instruction is critical to the academic success of candidates. To every Nigerian student; the mastery of the English language is critical to academic success; English being the language of instruction at all levels of education after the first three years of elementary education. Success in English language thus becomes a measure of success even in other subjects. This is particularly believed to be so because poor English proficiency has been found to maintain a correlation with poor performances in the other subjects (Mohammed, 1995). According to Ramezan and Setarah (2013), the sure step for countries such as Nigeria is just to strengthen the bases of knowledge, which is basically dependent on the quality of secondary education provided. They further maintain that training the children of these societies in the best way and making them ready for the present and future changes of the world.

Notwithstanding, Bamisaye (2004) opined that, in the context of Nigeria, the success or failure of a secondary school student largely depends on his/her ability to manipulate the English language through competent writing and speaking. The Poor SSCE results being recorded over the years has also put the educational system of Nigeria into a serious turbulence; revealing a sharp fall in the educational standard.

A study by Ariyo (2010) confirmed that, Nigerian secondary school students are so poor in both their oral and written English language and suggested that they obviously need to function adequately well in English to academically succeed. He further observed that, success can be achieved through employing appropriate learning strategies to master English. That can be achieved since English it is the medium of instruction across the Nigerian schools.

There is no doubt that secondary school education is a bedrock in determining the effectiveness of a national system of education and is also the pillar upon which higher education depends (Qaiser, Hassan, \& Ishtiaq, 2014) However, despite the fact that the Nigerian secondary school students are exposed to English language learning for the almost one decade covering the last three years of elementary school and the six years of high school, performance at the secondary school leaving certificate examination remains very poor for both English as well as other subjects (Oluwoye, 2008) with the highest achievement of 33percent in 2011 (Wike, 2011). These poor 
scores, due largely to poor mastery of English language at the level of secondary school, have been attributed to the manner in which the English language is taught and learnt. And among other factors inhibiting proper integration of strategy usage in learning it has put the Nigerian secondary education in a turbulent situation.

\subsection{Relationship between LLS, Learning Achievement and Socio-Economic Status}

Socio-economic status of learners' parents is also a factor that may contribute to English language proficiency. This is particularly because the rich household motivates learning among their wards, send them to good schools and live in an environment which in itself encourages learning. This is often not similar to situation in the poor household where the wards attend poorly managed, public schools, where teachers are inadequate, and even where they are available often over-loaded with additional duty responsibilities and or over-crowded classrooms.

Another dimension to socio-economic issue of the poor households includes the child's freedom to learn. While there may be adequate time for the child in the rich household to revise, in the case of a child from the poor homes engages in household chores and errands thereby leaving little or no time for learning at home. This has a bigger challenge to the poor in learning English language and to use a good strategy for communication.

English is a second language for the majority of Nigerian students as such it is imperative to investigate the manner in which it is learnt given the crucial position it represent in the education system as a whole and secondary education in particular. There is no doubt that, mastery of English language among secondary school students in Nigeria is fundamentally necessary as it serves as a determinant to success in other subjects.

Studies on second language acquisition have revealed that, learners' performance can be enhanced through employing certain language learning strategies (O'Malley \& Chamot, 1990; Rubin \& Thompson, 1994). Embi (2000) maintains that effective learners often are active information processors and interpreters who employ numerous strategies to store and retrieve information. Thus, employing numerous but appropriate language learning strategies (LLS) is considered fundamental in facilitating learning and mastery in the target language.

Learning a second language is a socio-psychological activity involving habit formation which is achieved through very active participation, adopting various learning strategies to effectively achieve a favourable performance of the learner in the production of the target language (Gardner, 1985; Noor, 2005; Nwogu, 2002). The attainment of communicative competence is often seen as a herculean task by the learner especially in an unfavourable environment. Previous studies have indicated that, employing learning strategies have the potentials to improve academic achievement. Similarly, socio-economic status of parents has been found to positively affect the learning ability of learners. Griffiths (2003) found a significant correlation between employing language learning strategies and the degree of mastering language. It is observed that, families of high socio-economic status have the potentials of making available all the needed resource for general subject learning which includes learning a second or foreign language; this cannot be emphasized for those of less SES. Similarly, Mattheoudakis and Alexiou (2009) found that, there are advantages that student from superior SES had over students of less socioeconomically advanced background. This was in agreement with other literature (Katsikas \& Kavvadias, 2000).

Previous studies have shown that, second language acquisition is greatly enhanced through employing appropriate learning strategies. From the outcome of this study therefore we could maintain that the respondents were quite active in employing learning strategies but may not be too effective because they employ more indirect learning strategies. For the respondents, social, Metacognitive and affective strategies, constituting indirect LLS, are more prioritized than the cognitive memory and compensation (direct LLS).

Apparently direct learning strategy use enhances the learning of all the four language skills. Thus, employing numerous but appropriate language learning strategies (LLS) is considered fundamental in facilitating learning and mastery in the target language, this was not well coordinated among the respondents.

\subsection{The Research Instrument/Questionnaire}

The instrument employed in this study is adapted from the SILL created by Oxford (1990) which has been extensively used in a number of previous studies (Ellis, 1994). The SILL was reported to have validity and a reliability of 0.846 . The original SILL was modified to create an instrument better suited to measure the target variable in the study are.

In the modified instrument, there were 2 additional categories of strategies; situational and religious strategies. In addition, as opposed to standard procedures of SES measures involving report of parental income or choice of income level, the research employed socio-economic status indicators such number of cars in the family, the hospital the family consults, the security level of the family, etc. These are practical considerations for SES measurement indicators in the study area and are believed to provide adequate data on the SES variable. The 
respondents in this study were secondary school students in their senior 2 level. At that level, they do not usually have information regarding parental income in the area of study, and attempting to extract such information for research purposes is bound to compromise the integrity of the data. On the contrary, it is easier and more accurate for learners to report on certain known measures of Socio-economic status in the society. This is employed for use in this study.

\subsection{State Hypotheses and Their Correspondence to Research Design}

The research was carried out in North Easter Nigeria within the secondary school students in Adamawa State. The research hypothesis to validate the survey is therefore stated thus:

$\mathrm{H}_{\mathrm{o}}=$ Thre is no statistically significant relationship between English Language Learning Strategies choice among secondary school students in Nigeria and their parents' socio-economic status.

$\mathrm{H}_{1}=$ Thre is statistically significant relationship between English Language Learning Strategies choice among secondary school students in Nigeria and their parents' socio-economic status.

\section{Method}

The data for this research was provided by 559 respondents who study English as a second language and in their senior level of secondary school education in Nigeria. The respondents for this study are homogenous in terms of their level of study, all been in their senior secondary level 2 (SS2) in the 2012/2013 academic year. Among the respondents, 27 , representing only 4.8 percent reported that their parents belong to the high level economic class; while 102 respondents or 18.3 percent have middle level economic class parents and 76.9 percent or 430 respondents' parents are within the lower level economic class.

\subsection{Method of Data Analysis}

Analysis of the data followed the use of SPSS version 16.0 to answer the first research question: What are the language learning strategies employed by secondary school students in Nigeria while learning English? A one-way ANOVA was conducted to answer the other research question: is there any significant relationship between parents' socio-economic status in Nigeria and secondary school student's choice of Language learning strategy used in learning English?

\subsection{Reliability of Research Instrument}

The reliability analysis of the modified instrument yielded an overall Alpha Cronbach's value of .816, indicating items are very reliable. The instrument features eight categories of learning strategies with situational and religious strategies added to sub-sections of the original Study Inventory of Language Learning (SILL).

\section{Results}

\subsection{Overall Language Learning Strategies Employed}

The analysis of the Language Learning Strategy (LLS) employed by the secondary school students in Nigeria indicated that eight categories of learning strategies were employed at differen level of utilization based on Oxford (1990) scale of measurement. The strategies employed by the students are memory, cognitive, compensation, meta-cognitive, affective, social, situational and religious. The result of the strategies been employed for learning English language is presented in Table 1. The rate of employment of the strategies though varies indicated that they are al employed at high frequency level.The level of usage is presented also in table 1.0 which varies between 4.2224 for Social Strategy and 3.4010 for Compensation strategy. Also the rank of the various level of usage is shown in the table.

Table 1. Overall learning strategies employed by secondary school students in Nigeria

\begin{tabular}{llll}
\hline Strategy categories & Respondents & Mean of usage & Rank \\
\hline Social & 559 & 4.2442 & $1 \mathrm{st}$ \\
Meta-cognitive & 559 & 4.2184 & 2nd \\
Affective & 559 & 4.0863 & $3 \mathrm{rd}$ \\
Situational & 559 & 3.9445 & 4 th \\
Cognitive & 559 & 3.9379 & 5 th \\
Memory & 559 & 3.7835 & 6 th \\
Religious & 559 & 3.7722 & 7 th \\
Compensation & 559 & 3.4010 & 8 th \\
\hline
\end{tabular}


Apparently, respondents in this study employed most of the learning strategies within closely related frequency level. For instance, seven of the learning strategies reported were employed within the range of 4.2442 and 3.7722 which is high according to Oxford (1990) mean score range interpretation. Only compensation strategy recorded a mean score of 3.40 and therefore categorized under the medium rank.

The descriptive analysis of the employed strategies by the respondents is discussed in detail in the discussion in ascending order of its importance to the respondents at the discussion sub-section. The most preferred strategy is social while the least strategy is compensation. The analysis of the strategies are grouped hierarchically thus: the first three, that is social, metacognitive and affective are classified as high level strategy by the respondents; situational and cognitive strategies as classified as medium used strategy while memory, religious and compensation strategies as hierarchically considered as low level strategy employed by the respondents in this study.

\subsection{Test of the Hypothesis}

The research hypothesis as stated earlier is therefore tested to determine whether there is statistically significant relationship between English Language Learning Strategies choice among secondary students in Nigeria and their parents' socio-economic status. To achieve this, One-way-Analysis of Variance (ANOVA) was employed at $5 \%$ level of significance, as shown in Table 2.

Table 2. ANOVA of English language learning strategies choice among secondary students in Nigeria and their parents' socio-economic status

\begin{tabular}{|c|c|c|c|c|c|c|}
\hline Dependent Variable & Source of Variation & Sum of Squares & $\mathrm{dF}$ & Mean Sq & $\mathrm{F}$ & P Value \\
\hline & Between Groups & 7.351 & 5 & .490 & & \\
\hline \multirow[t]{3}{*}{ Memory } & Within Groups & 185.605 & 48 & .342 & 1.43 & .126 \\
\hline & Total & 192.927 & 53 & .345 & & \\
\hline & Between Groups & 7.616 & 5 & .508 & & \\
\hline \multirow[t]{3}{*}{ Cognitive } & Within Groups & 126.541 & 48 & .233 & 2.18 & .006 \\
\hline & Total & 134.157 & 53 & - & & \\
\hline & Between Groups & 10.040 & 5 & .669 & & \\
\hline \multirow[t]{3}{*}{ Compensation } & Within Groups & 274.094 & 48 & .505 & 1.33 & .181 \\
\hline & Total & 284.134 & 53 & - & & \\
\hline & Between Groups & 10.314 & 5 & .688 & & \\
\hline \multirow[t]{3}{*}{ Metacognitive } & Within Groups & 161.246 & 48 & .297 & 2.32 & .003 \\
\hline & Total & 171.560 & 53 & - & & \\
\hline & Between Groups & 17.292 & 2 & 1.15 & & \\
\hline \multirow[t]{3}{*}{ Affective } & Within Groups & 187.856 & 556 & .346 & 3.33 & .000 \\
\hline & Total & 205.148 & 558 & - & & \\
\hline & Between Groups & 16.645 & 5 & 1.110 & & \\
\hline \multirow[t]{3}{*}{ Social } & Within Groups & 167.885 & 48 & .309 & 3.59 & .000 \\
\hline & Total & 184.630 & 53 & & & \\
\hline & Between Groups & 40.297 & 5 & 2.686 & & \\
\hline \multirow[t]{3}{*}{ Situational } & Within Groups & 290.105 & 48 & .534 & 5.03 & .000 \\
\hline & Total & 330.392 & 53 & - & & \\
\hline & Between Groups & 57.171 & 5 & 3.81 & & \\
\hline \multirow[t]{2}{*}{ Religious } & Within Groups & 407.940 & 48 & .884 & 4.31 & .000 \\
\hline & Total & 537.217 & 53 & - & & \\
\hline
\end{tabular}

From the Table 2 it can be observed that there is significant difference between socio-economic status of parents (high, middle or lower class) and most LLS used by secondary school students in Nigeria while learning English language. The hypothesis is rejected but for the following strategies: Memory $(F=1.434$, sig $=.126 \geq P$ Value $=$ $0.05)$, cognitive $(F=2.179$, sig $=.006 \geq$ PValue $=0.05)$ and Compensation $(F=1.326$, sig $=.181 \geq$ Pvalue $=$ 0.05). This result implies that, the socio-economic status of the respondents family has effect on the learner use of memory, cognitive and compensation LLS but has no significant effect on Metacognitive $(F=2.316$, sig 
$=.003 \leq P$ Value $=0.05) ;$ Affective $(F=3.332$, sig $=.000 \leq P$ Value $=0.05) ;$ Social $(F=3.589$, sig $=.000 \leq P$ Value $=0.05) ;$ Situational $(F=5.027$, sig $=.000 \leq$ Pvalue $=0.05)$ and Religious $(F=4.311$, sig $=.000 \leq P$ value $=0.05$ ).

The above findings implied that, learners of English language at the level of secondary schools in Nigeria differ in employing memory, cognitive and compensation learning strategy as a result of their parent's socio-economic status. It may be deduced that, learners that are less affluent background may be encountering leaning challenges due to non availability of learning facilities that provides balance opportunities to all.

However, irrespective of their parents' socio-economic levels they do not significantly differ in employing metacognitive, affective, social, situational and religious LLSs.

\section{Discussion}

The analysis of the high level hierarchy strategies employed by the respondents from this survey indicated that three strategies are the most preferred by the respondents. These strategies are the social, metacognitive and affective strategies. The analyses of the respondents' responses to these strategies are presented thus:

Social strategy is a hierarchical skill related to communication, teamwork, management and leadership. It involves interpersonal performance in the larger range of social context in which learning occurs. The analysis of social strategy indicated that it is the most preferred strategy employed among secondary school students in Nigerian while learning English as a second language. The average mean score of social strategy is 4.09 and standard deviation of 0.86 . The implication of this is that they employ social strategy at high frequency. The analysis shows that the respondents believe in the usage of social interaction to learn English language. This has been aided by the availability of many social network that makes interaction more easier than before, communication across all platforms of social media are enhanced with the ability to speak English language. This may have aided the respondents' preference of social strategy.

Learning generally depends on the learner readiness to learn. By this, it implies that learning can only be effective if the learner is ready both physically and mentally. The analysis of meta-cognitive strategy use indicated that it is being employed more often and aid their retentive ability. The range of mean score of the usage of Metacognitive strategy is 4.22 and its standard deviation is 0.91 . This strategy is been employed at high level. This implies that the students can recollect, retain and reproduce what has been learnt.

Affective strategy is a linked to learning process that emphasize on learning tone and emotion or degree of acceptance or rejection. It however varies from simple attention to control of emotion. That is from simple phenomena to more complex issues that are internally consistent with qualities of character and consciousness of respondents. This is a strategy that allows the respondents to think and relate the language been learnt emotionally so as to feel the sense of belonging. The analysis of affective strategy been employed by the respondent shows that the mean score is 4.09 while the standard deviation is 0.96 . There is high mean score which implies that affective strategy is highly employed among the respondents. This may be due to the fact that emotional issues have an important relation with one's ability to relate very well in the society. Nigerian environment because of its multi ethnic has adopted English as official language and mistakes in English are not condone. As a result even at secondary school level emotion is attached to both spoken and written English language.

Result of the analysis of situatioal strategy indicated that there is high usage of this category of learning strategy also by the Secondary school students in Nigeria to facilitate learning English language. This is a method of communication outside the classroom or the syllabus of teaching and learning. The situational strategy is an informal way of learning English language through communication with parents, peers, teachers, hostel master and neighbors within the vicinity of respondents. The mean score for situational strategy usage is 3.95 and standard deviation 1.08. This implies high level of usage among the respondents.

Cognitive strategy allows learners to use their mental ability to acquire linguistic knowledge through employing appropriate thoughts and experience. It is a perception, sensation, idea or intuition from the process of cognition. This strategy is used to assess the ability of students to learn English language in secondary schools in Nigeria. The result of analysis of cognitive strtagy indicated that the mean score is 3.94 and its standard deviation is 1.09 . The means is slightly lower compared to other strategies while the standard deviation is higher than 1.0. This implies that there is strong disparity among the standard deviations of the items. The disparity may be due to the fact that cognitive learning strategy encompasses all the four skills of language that is skill of speaking, listening, reading and writing. 
Memory is the ability of the learner to keep, retain and recall information and experience learnt. In second language learning the ability to retain and recall from the target language is crucial. When a learner employs useful strategies to help him/her in the task of Second language learning, that make learning process easier. The analysis shows that the mean value of memory strategy 3.78 and standard deviation of 1.13 . The implication of this is that there is wide variation among the usage of this strategy. This may be due to respondents varied ability to retain and recapitulate what had been learnt. The analysis implies that the respondents employed memory strategy less because of their low level of retention, recapitulation and practice. They pay less attention to their studies, lack language learning creativity such as using flashcards, connecting sounds, mental picture of circumstances and spending quality time on less profitable activities that does not help them academically.

Religion is communication with the creator and the ability of the learner to interact with the Supreme Being has always been the origin of wisdom. Religion plays a role in allowing students to learn second language as preaching, sermon and religious books are also available in English. Because of multi cultural and multi tribal nature of Nigeria and the adaptation of Islamic and Christianity brought to the country many of the holy books and are also written in English language as well as some local languages and both religions teach and encourage reading, recitation, and memorization. When a learner employs useful strategies to help him/her in the task of Second language learning that makes learning process easier. The analysis of the research data indicated that the mean average score for religious strategy is 3.77 while standard deviation is 1.29 . The disparities between the two end shows that religion plays a lesser role as a strategy in language learning of the respondents.

Compensation language learning strategy is usually employed to facilitate students learning ability as it relates to filing the missing gaps in vocabulary, phrases or sentences. This involves using gestures, guesses and synonyms to convey meaning to language been studied. Compensation aid the learner to understand more about the usage of the target language. The analysis of compensation strategies employed by secondary school students in Nigeria when learning English language indicated that it is the least employed of all the eight strategies. The average means score value of compensation strategy as employed by respondents' is 3.40 and standard deviation 1.24. The mean score value of compesational strategy is 3.40 and the standard deviation is 1.25 . Hence it is an indication that Compensation strategy to learn English language among the respondents is employed on medium level.

However, due to differences in socio-economic status of respondents' parents, the process of employing these strategies in learning English language differs due to different enabling learning environment. Consequently, to facilitate cognition, memory and practice of the new language, the affluent learner may enjoy the use of numerous learning chances such as current practical books in learning English, watching TV, using computers, Video games, having lesson teachers to converse with, etc. while the less affluent learner socializes with teachers and fellow students in and out of classroom and plan for their study in the midst of all challenges, lacking basic support to aid cognition, memory and compensation strategies.

\section{Conclusion and Recommendations}

The pattern of strategy employment as revealed showed that, social strategy was the most frequently used strategy while religious strategy was the least in usage. The correlation between parent's SES and the choice of learning strategies indicated there was difference among respondents in the choice of memory, cognitive and compensation but no difference in the choice of metacognitive, affective, social, situational and religious LLS and parent's SES among secondary school students in Nigeria.

In order to bridge this gap strategy use should be integrated into English language school curriculum to provide students from less affluent backgrounds with learning opportunities and support that are obviously not available at the home level with emphasis on the use of improvised learning aids to cognition.

The personal use of aids such as flash cards, reading short story books that are available in the school library and engaging in academic extra-curricular activities, such as press clubs, debating and drama clubs should also be taught and encouraged among learners with opportunities for language practice with colleagues and better learners. Where such clubs do not exist, Principals and English language teachers should be supported to establish them.

Government should also make adequate provision to equip secondary schools with relevant educational technology including modern ICT-based language laboratories especially in rural areas where such facilities are not readily available and where the economy of the dwellers is generally inadequate and parents are mostly uneducated. 


\section{References}

Abimbola, W. (2010). Yoruba Language under threat of extinction. Retrived June 17, 2011, from http:/www.nigeriafilms.com/news/9569/21/yoruba-language-under-threat-of-extinction-abimbol.html

Adeyemi, T. O. (2012). School variables and internal efficiency of secondary schools in Ondo State. Nigeria J. Educ. Soc. Res., 2(3), 205-214. http://dx.doi.org/10.5901/ijesr.2012v2n3p205

Bamisaye, T. O. (Ed.). (2004). An Overview of Sociolinguistics and the English Language in an Integrated Study in Language and Society 1. Lagos: MAJAB Publishers.

El-Dib, M. A. B. (2004). Language learning strategies in Kuwait: Links to gender, language level, and culture in a hybrid context. Foreign Language Annals, 37(1), 85-95. http://dx.doi.org/10.1111/j.1944-9720.2004.tb02176x

Ellis, R. (1994). The Study of Second Language Acquisition. Oxford: Oxford University Press.

Gardner, R. C. (1985). The attitude/motivation test Battery. Technical Report. Ontario: University of West Ontario.

Griffiths, C. (2003). Language learning strategy use and proficiency: The relationships between patterns of reported language learning strategy (LLS) use by speakers of other languages (SOL) and proficiency with implications for the teaching/learning situation (PhD Dissertation, University of Auckland).

Jaiyeoba, O. A., \& Atanda, I. A. (2011). School Quality Factors and Secondary School Students' Achievements in South-Western and North-Central Nigeria. The African Symposium: An online journal of the African Educational Research Network. Retrieved April 28, 2014, from http://www.ncsu.edu/aern/TAS11.1/TAS11.1_JaiyeobaAtanda.pdf

Katsikas, C., \& Kavvadias, G. K. (2000). I anisotitastinellinikiekpaidefsi [Inequality in Greek education]. Athens: Gutenberg.

Ariyo, K. S. (2010). A study of the Language Learner Strategies Adopted by Nigerian Students. Pakistan Journal of Social Sciences, 7, 433-436. http://dx.doi.org/10.3923/pjssci.2010.433.436

Mattheoudakis, M., \& Alexiou, T. (2009). Early foreign language instruction in Greece: Socioeconomic factors and their effect on young learners' language development. In M. Nikolov (Ed.), The age factor and early language learning (Studies on language Acquisition) Language Acquisition) (pp. 227-252). Mouton de Gruyter. Nikolov_10_Ch10. Times NRMT 1120 Jiang (SOLA).

Matthew, I. A. (2013). Provision of secondary education in Nigeria: Challenges and way forward. Journal of African Studies and Development, 5(1), 1-9. http://dx.doi.org/10.5897/JASD11.058

Mohammed, A. (1995). Communicative Competence Acquisition in Infelicitous Learning Environments: The Problem with SSS English in Nigeria. In A. Bamgbose, A. Banjo, A. Thomas, \& L. A. Banjo (Eds.), New Englishes: A West African Perspective. Ibadan: Mosuro Publishers and Booksellers.

Mohamed, A. E. (2000). Language learning strategies: A Malaysian context. Bangi. Fakulti Pendidikan, Universiti Kebangsaan Malaysia.

Munkaila, M., \& Haruna, A. (2001). Motivations and attitudes: The case of German students learning Hausa language. In H. Igboanusi (Ed.), Language Attitude and Language conflict in West Africa.

Noor, Z. A. (2005). Investigating Students' motivational orientations when learning English in the ESL Classroom. In Ambigapathy (Eds.), Strategies and practices for improving learning and literacy. Universiti Putra, Malaysia Press.

Nwogu, K. N., \& Nwoke, A. (2002). A handbook for English language teaching in Nigerian Secondary schools. Jos Norton Publishers.

Oluwoye, D. A. (2008). The Impact of Mother Tongue on studnets' Achievemant in English Language in junior Secondary Certificate Examination in Western Nigeria. J Soc. Sci., 17(1), 41-49. Retrieved June 24, 2014, from http://www./02-Journals/JSS/JSS-17-0-000-000-2008-Web/JSS-17-1-001-08-Abst-Text/JSS-17-1-04108-590-Oluwole-D-A/JSS-17-1-041-08-590-Oluwole-D-A-Tt.pdf

O’Malley, J. M., \& Chamot, A. U. (1990). Learning strategies in second language acquisition. Cambridge: Cambridge University Press.

Osbon, D. (2007). How English threatens indigenous languages Sunday, July 8. Retrieved from http://www.thetidenews.com/article.aspx?qrDate=07/08/2007\&qrTitle=How\%20English $\% 20$ threatens $\% 20 \mathrm{i}$ ndigenous $\%$ 20languages\&qrColumn=SUNDAY\%20EXTRA 
Oxford, R. L. (1990). Language learning strategies: What every teacher should know. New York: Newbury House.

Oxford, R. (2003). Toward a More Systematic Model Pf L2 Learner Autonomy. In P. Palfreyman, \& R. Smith (Eds.), Learner Autonomy across Cultures: Language Education Perspectives (pp. 75-91). Great Britain: Palgrave Macmillan.

Oxford, R. L., Cho, Y., Leung, S., \& Kim, H.-J. (2004). Effect of the presence and difficulty of Task on Strategy Use: An Exploratory Study. International Review of Applied Linguistics, 42, 1-4.

Oyetade, S. O. (1990). Nupe-Yoruba Endoglossic Bilingualism in Saare/Tsaragi community in Kwara state (Unpublished Ph.D. Thesis), University of Ibadan, Nigeria.

Qaiser, S., Hassan, D. A., \& Ishtiaq, H. (2014). Effects of Classroom Physical Environment on the Academic Achievement Scores of Secondary School Students in Kohat Division, Pakistan. International Journal of Learning and Development, 4(1), 71-82. http://dx.doi.org/10.5296/ijld.v4i1.5174

Ramezan, J., \& Setareh, M. (2013). Education in 21st Century. International Journal of Learning and Development, 3(6), 19-25. http://dx.doi.org/10.5296/ijld.v3i6.4607

Rubin, J., \& Thompson, I. (1994). How to be a more successful language learner (2nd ed.). Boston, MA: Heinle \& Heinle.

Nyeson, W. (2011). Federal Government discards appeal to fund Private schools. Daily sun Newspaper, September 6th.

\section{Copyrights}

Copyright for this article is retained by the author(s), with first publication rights granted to the journal.

This is an open-access article distributed under the terms and conditions of the Creative Commons Attribution license (http://creativecommons.org/licenses/by/3.0/). 